\title{
EFFECT OF SHELL ENDS CN THE CONTACT PROBLEMS
}

MIIITARY TECHNICAL COLLEGE

CAIRO - EGYPT

1
Z. Z. MOHEH ${ }^{*}$,

F. EL-SHER IF

\begin{abstract}
\end{abstract}
The effect of shell ends on the contact problems of saddle supporting cylindrical shell is solved using the semi-bending theory of shells. The saddle / cylinder interface pressure and the stress distributions are found for different saddle angles, for both welded saddle and not welded saddle. The injn. distance of the saddle posjtian from the shell end is found such that the end has no effect on the atress at the saddle positions. The circunferential stresses at the plane of middle profile of the saddle are found experimentally using etrain gauge. The experimental results are in good agreenent with those: obtained from numerical analysis.

\section{INTRODUCTION}

In spite of the importance of the contact problem of supporting shells, it has not been precisely solved. Twin saddle supports: are the most frequentely used type of supports for horizontal vessels. The published works treated special cases of this problem by using the generalized bending theory of shells $[1,5]$ or : the semi-bending theory of shells $[2,3,4]$. They consider the: shell either infinitly long or finite with clasical boundary

çonditicns. So far semi-empirical methods have been used for design purpose to predict the peak values of stresses[6]. These values of stresses depend on the shell parameters, half saddle angle $(B)$, shell end conditions and manner of connections of the saddle to the cylinder. In the present work we consider a. semi-infinite long cylindrical shell with free ends rested on: two saddles with vertical load (F) at mid length of shell Fig.I. This work studies the effect of the shell ends on the stresses and interface pressure distritutions, for welded and not welded. saddle, and attenpts to pressent a simple analytical solution For this problem. The solution determinesthe distribution and magnitude of the radial saddle/cylinder interface pressure,

* Graduate student, *** Professor, Dept. of Machine Design, Faculty of Engineering and Technology, Mataria-Cairo. * Col.Dr. Dept. of Mechanics and Elasticity,Military Technical college, Cairo. 
then the stress resultants, and displacements throughout the ivessel are calculated. The solution is based on using the so called semi-bending theary of shells with compressible middle: surface for deriving the influence line due to the radial. unit load [7]
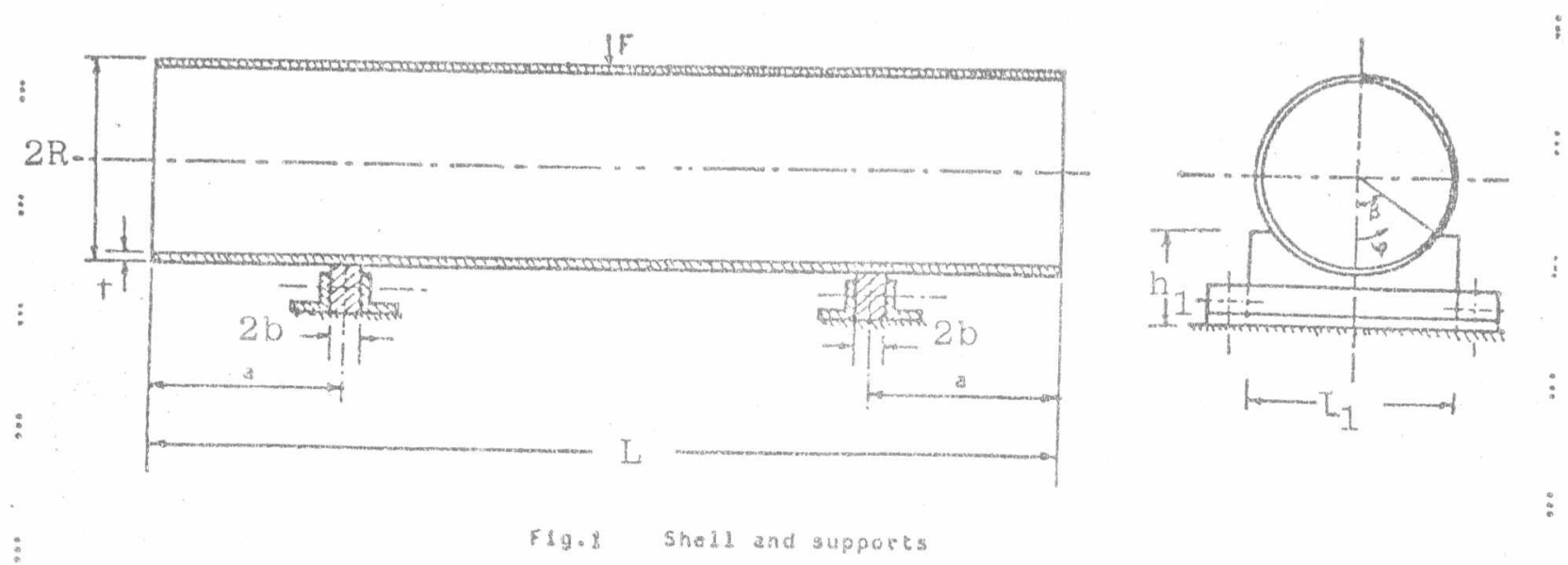

\section{GOVERINING DIFFERENTIAL EQUATIONS}

In the presert work the generalized semi-bending theory with compressible middle surface is used in dexiving the required equations. The basic assumption of this theory is the negligence of the increment in curvature of the shell in the axial directior. The principle of minimum potential energy is used for deriving the differential equation. By studying the equili- : brium of the shell elenent Fig.2. and the shell deformation, the following differential equation is obteined:$\vdots$

$$
N_{h}^{\prime \prime \prime}(x)-2 a N_{n}^{\prime \prime}(x)+b_{n}^{2} N(x)=c
$$

where, $M(x)$ is the longitudinal normal force and primes indicate differentiation with respect to $x$ and

$\therefore \quad a_{n}=\frac{t^{2}}{R^{4}} \frac{a^{2}\left[1+\mu-n^{2}(2+\mu)+n^{4}\right]}{12+\delta^{2} n^{2}\left[n^{2}+\frac{12}{5}(1+\mu)\right]}$

$\vdots \quad b_{n}=\frac{t}{R^{3}} \frac{n^{2}\left(n^{2}-1\right)}{12+\delta^{2} a^{2}\left[n^{2}+\frac{12}{5}(1+\mu)\right]}$

$\quad \quad c_{n}=\frac{\mu \varepsilon^{2}}{\pi R^{6}} \frac{n^{4}\left(n^{2}-1\right)^{2}}{12+\delta^{2} n^{2}\left[n^{2}+\frac{12}{5}(1+\mu)\right]} \mathbb{N}_{(x)}$

$\vdots \quad \Phi^{N}(x)=\S T_{S}^{\circ} \cos \pi \psi d \psi$

$i_{s}^{0}$ normal force in circumferential direction at $n=1$. 
$: \delta=t / R, t$ is the thickness of the shell, $R$ is the shell radius and $\mu$ is the poisson's ratio.

$\vdots$

!

$\vdots$

:

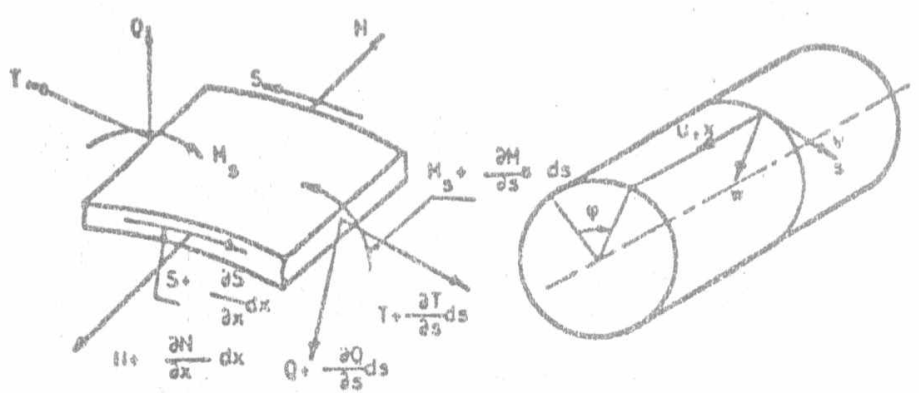

Fig. 2.

$\vdots$

SOLUTION OF DIFFERENTIAL EQUATION AND
DETERMINATION OF THE INFLUENCE LINES.

Consider a circular cylindrical shell with semi-infinite length subjected to a unit surface load in the interval from $x^{\circ}=a-b$ up to $x=a+b$ as shown in Fig. 3. The surface load has a very small angle. Expressing the load by fourier series and solving the corressponding differential equation using the boundary conditions of the shell end (free ends), the influence lines for unit radial surface load takes the following forms:!

$$
\begin{array}{ll}
\vdots & w_{R}(a, \varphi)=\frac{1}{\vec{E} H}\left(\frac{R}{t}\right)^{5 / 2} F_{W R} \\
\vdots & w_{R}(a, \varphi)=\frac{1}{E R}\left(\frac{R}{t}\right)^{5 / 2} F_{V R} \\
a_{S R}(a, \varphi)=\frac{1}{t^{2}}\left(\frac{t}{R}\right)^{\frac{3}{2}} F_{S R} \\
\quad E^{-\infty}=\frac{E}{1-\mu^{2}}
\end{array}
$$
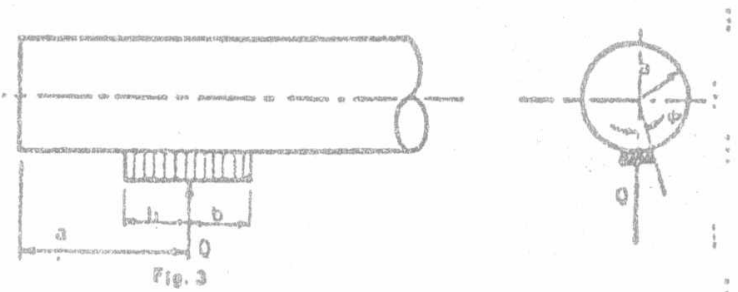

where, $w_{R}$ is the radial displacement, $v_{p}$ is the tangential displacement and $\sigma_{S R}$ is the circumferential notmal stress at the giddle profile of the saddle.

For compressible middle surface and $b_{n}^{2}>a_{n}^{2}$;

$\vdots$

$$
F_{W R}=-\frac{6}{\pi k_{1} \sin \varphi} \sum_{n=2}^{n=\infty} \frac{\sin n \phi \cos n \varphi}{n\left(n^{2}-1\right)^{2}} F_{1 n}
$$

:

$F_{V R}=-\frac{6}{\pi K_{1} \sin \phi} \sum_{n=2}^{\infty}\left[\frac{1+A n^{2}\left(n^{2}-1\right)}{n^{2}\left(n^{2}-1\right)^{2}} F_{\ln }-\frac{\mu \delta^{2}}{12\left(1-\mu^{2}\right) R^{2}} F_{2 n}\right] \operatorname{sinn} \psi \sin n \phi$

i... 


$$
\begin{aligned}
& F_{\text {S A }}=-\frac{3}{b \sin \phi} \sum_{n=2}^{\infty} \frac{\sin n \phi \sin n \varphi}{n\left(n^{2} \cdots 1\right)} F_{1 n} \\
& F_{1 n}=-e^{-\omega} k_{1} \cos x_{1} k_{1}+\frac{\omega_{1}^{2}-r_{1}^{2}}{2 \omega_{1} x_{1}} e^{-\omega_{1} k_{1}} \sin x_{1} k_{1}+x_{4}+1 \\
& \therefore \bar{\lambda}_{1}=e^{-\omega} 1^{\left(2 k_{2}+k_{1}\right)} \cos r_{1}\left(k_{2}+k_{1} j-e^{-\omega_{1}\left(2 k_{2}-k_{1}\right)} \sin r_{1}\left(k_{2}-k_{1}\right)\right.
\end{aligned}
$$

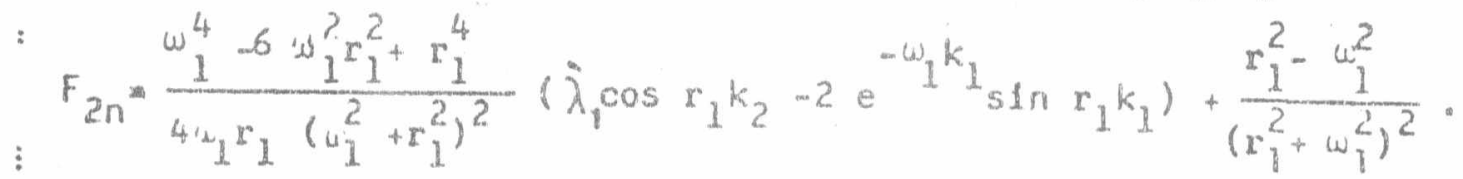

$$
\begin{aligned}
& \left(\bar{\lambda}_{2} \cos r_{1} k_{2}+2 e^{-\alpha 1} k_{1} \cos r_{1} k_{1}-2\right)+\lambda_{3} \text {. } \\
& \dot{\lambda}_{2}=e^{-\mu 1^{\left(2 k_{2}+k_{1}\right)}} \cos r_{1}\left(k_{2}+k_{1}\right)-e^{--1)\left(2 k_{2}-k_{1}\right)} \sin x_{1}\left(k_{2}-k_{1}\right) \\
& \vdots \dot{\lambda}_{3}=\left(\frac{\omega_{1}^{4}-4 \omega_{1}^{2} r_{1}^{2}-r_{1}^{4}}{2 r_{1}^{2}\left(\omega_{1}^{2}+r_{1}^{2}\right)^{2}} \lambda_{1}+\frac{7 \omega_{1}^{4}-2 \omega_{1}^{2} r_{1}^{2}-r_{1}^{4}}{4 \omega_{1} r_{1}\left(\omega_{1}^{2}+r_{1}^{2}\right)^{2}} \lambda_{2}\right) \text { sin } r_{1} k_{2} \\
& : \quad \dot{\lambda}_{4}=\left(\dot{\lambda}_{1} \dot{c}_{1}-\dot{\lambda}_{2} \dot{c}_{3}\right) \cos r_{1} k_{2}+\left(\dot{\lambda}_{1} \dot{c}_{2}+\dot{\lambda}_{2} \dot{c}_{4}\right) \sin r_{1} k_{2} \\
& \vdots c_{1}=\frac{12 \omega_{1}^{2} r_{1}^{2}-3 w_{1}^{4}-r_{1}^{4}}{4 \omega_{1} r_{1}\left(\omega_{1}^{2}+r_{1}^{2}\right)}, \quad c_{2}=\frac{\omega_{1}^{4}-5 w_{1}^{2}+2 r_{1}^{4}}{2 r_{1}^{2}\left(w_{1}^{2}+r_{1}^{2}\right)} \\
& \therefore c_{3}=\frac{4 \omega_{1}^{2}-3 r_{1}^{2}}{2\left(\omega_{1}^{2}+r_{1}^{2}\right)}, \quad c_{4}=\frac{7 w^{4}-8 w_{1}^{2} r_{1}^{2}+r_{1}^{4}}{4 w_{1} r_{1}\left(w_{1}^{2}+r_{1}^{2}\right)}, w=\sqrt{\frac{1}{2}\left(b_{n}+a_{n}\right)} \\
& \vdots \\
& \omega_{1}=\frac{R \omega}{\sqrt{\delta}}, r_{1}=\frac{R \cdot r}{\sqrt{\delta}}, k_{1}=\frac{b}{k} \sqrt{\delta}, k_{2}=\frac{a}{R} \sqrt{\delta}, \quad r=\sqrt{\frac{1}{2}\left(b_{n}-a_{n}\right)}
\end{aligned}
$$

This work will attempt to pressent a simple analytical solution for the contact problen: The solution determines the distribution and magnitude of the radial interfaco pressure, then the stress and displacenent resultants throughout the vessel are calculated. Throughout the analysis, the following assumptions are made:-

1. The saddle is rigid conpared with the cylinder i.. 
2. The pressure distribution accross the saddle vidth is constant, see Ref. [I]

3. The self weight of the lessel is smalj compared with the : external applied load and is neglected.

If the required sadalies are possitioned equidistance from both : ends, with the ceritres of the saddle arcs on tha same cylin'der generator, then the distribution and magnitude of the inter-; face pressure is the same for both saddles.

For deriving the continuity equations, the saddle contact surface is divided into $2 \mathrm{~N}$ :rectangular sections, each of axial lerigth $2 b$ equel the saddle width and corresponding to the icircumferential lergtio $o_{j}$ with the section of the angle $\Delta \psi_{j}$,

Fig.4. Each section of area 2b. $\Delta j$ is loaded by a uniform radial pressure $x_{i}$. Then the total radial displacement of the cylinder profile at point i due to all the radial interface pressure is given by :-

\section{$\vdots$}

$\vdots \quad w_{i}=\sum_{j=I}^{2 N} x_{j} \cdot W_{R i j}$

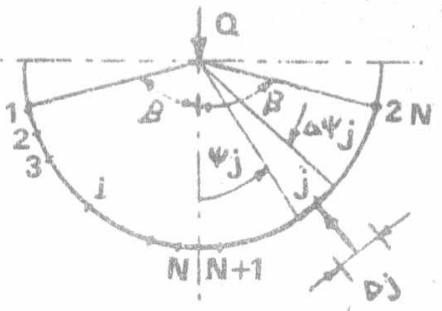

Madlal load In the plane of the saddle proplite. B। 
\begin{tabular}{|l|l|l|l|l|l|}
\hline $\mathrm{MDB}-14$ & 150 \\
\hline
\end{tabular}

FIEST $2 . M$. CONEERENCE

29-31 lià 1984, Cäiro

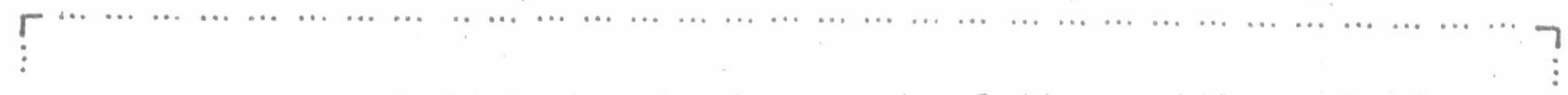

$k$ : vertical rigid body aisplacement of the saddie relative : to the sheli end.

The equilibrium equation of tre vessel Fig. 4. is

$$
\quad Q=\sum_{i=1}^{2 N} x_{i}^{2} \cdot \cos \psi_{i}
$$

Solving the continuity equation (6) together with the equilibriuni equation ( 7 ), the magnitudes of the radial interface pressure car be found, then the displacements and the stress : iresultants throughout the vessel car be determined. For a crossection passing through the saddle center profile, at any point $i$ on the cylinder, the total radial displacement is giver by equ. (5).

The tota? tarigential displacement is:$\vdots$

$$
\vdots \quad v_{i}=\sum_{j=I}^{2 N} \cdot x_{j} v_{R i j}
$$

:and the total circumferential stress is:-

$$
\vdots \quad \sigma_{s i}=\sum_{j=I}^{2 N} x_{j} \sigma_{s R i j}
$$

$\vdots$

Where, $V_{R i j}, \sigma_{s R i j}$ are the circumferential displacement and : circumferential stress at point (i) due to a unit radial interface pressure acting over the area at point $j$ on the same profile.

A program was writteri for solving the problem using ICL com: puter with the follewing steps.

1. Calculation of the influence line: eqn. (3). In this step $\vdots$ a quick convergance series representation for the influ- : ence lines are used.

2. Formation of the continuity equation (6)

:3. Solving the continuity equation together with the equili- : brium eqn. (7) to determine the saddle/eylinder interface pressure using Gaussian salution.

:4. Calculate the displacements and stresses using eqs. $(5,6,7)$ :

Data were prepared for the solution of an example of a model : cylinder with the following dimentions: Radius $R=250 \mathrm{~mm}$, Length $\mathrm{L}=2900$ mm, Thickness $t=9 \mathrm{~mm}$, i. 


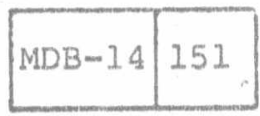

FIRST A.M.E. CONFERENCE

29-31 May 1984, Cairo

Shell rigidity $K_{I}=\frac{b}{R} \sqrt{\delta}=0.02372$, half saddle angle $\beta=16^{\circ}$ and $60^{\circ}$, sadle width $2 b=360 \mathrm{~m}$, Poisson's ratio $\mu=0.3$, modulus: of elasticity $E=2 \times 10^{3} \mathrm{HP}$ and different shell end factor $\dot{k}_{2}=\frac{a}{R} \sqrt{\delta}$ with various values for the distance "a"

ANALYSIS AND DISCUSSIONS

:

Studying the interface pressure distributicn for different values of $\mathrm{K}_{2}$, for welded saddle Fig. 5.g and for not welded saddle Fig. ${ }^{2}$.. we conclude that the magnitude of the interface pressure $(X)$ for velded saddle is greater than the corresponding values in not velded saddle, but it has zero values at areas where negative sign appears for welded saddle. To obtain the distribution of the radial interface pressure $(x)$ : for not welded saddle, we can use the same computer program for welded saddle, but when the contact is lost at any section the interface pressure must be zero. This condition can be easily incorporated into the program by examining the sign of the resulting interface pressure, where they occured as negative values, remove the corresponding row and column in the matrix $\left[W_{R}\right]$. Set the descret negative load $(x)$ equal to zero in the loading vector IXl and repeat, the calculation.

The contact will take place at the saddle horn and middle pointiof the: prefile of thes saddle for $\beta=16^{\circ}$. For $\beta=40^{\circ}$ a surface of contact will develop in the central part of the support. $:$ For $B=60^{\circ}$, the contact area in the central part of the saddle arc will increase up to $\psi=36^{\circ}, F i g .7$.

The maximum of stress coefficient Fsmax. decreases with the : increase of $k_{2}$ upto $k_{2}=0.3$, Fig. 8,9. For $k_{2}>0.3$, F $F_{\text {smax }}$ has approximately a constant value. Therefore, the circumfer-: :ential stress $\sigma$ s throughout the vessel in the saddle region is not affected with the shell end conditions for $a \geqslant 0.3 R / \sqrt{8}$ Fig. 10, shaws that the maximum circumferential stress (at the saddle horn) for not welded saddle is less thar the correspinding values for welded saddle by $26 \%$

When the saddle arc is divided into $2 \mathrm{~N}$ sectiors with $\Delta \psi \mathrm{j}=\mathrm{B} / \mathrm{N}=$ : $4^{\circ}$ or $1^{\circ}$, we notice thit the numerical results for $N=I^{\circ}$ are in good agreement with those experimental results Fig. II Fig. 12. shows the numerical results of stress for infinitly long shell, $\operatorname{Ref.}[5,6]$, also for semi-infinite length shell; of which we notice that the experimental results are in good : a greement with those obtained for semi-infinite length. 


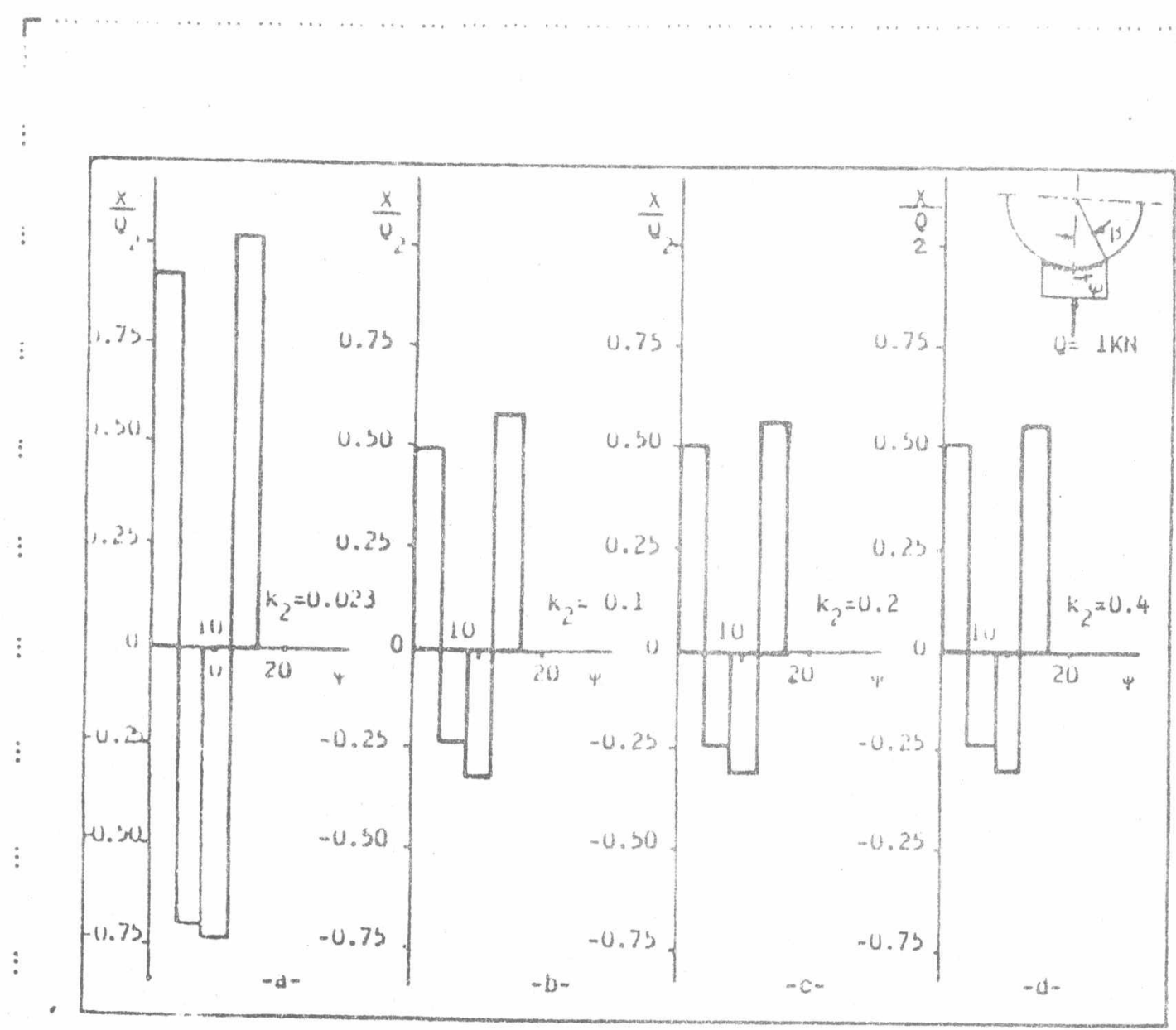

Fig.5. Interface pressure distribution for wedded saddle, different values of $K_{2}$ and $\left(\Delta \phi=4^{\circ}, \beta=16^{\circ}, k_{1}=0.02372,0=0.036\right)$ due to

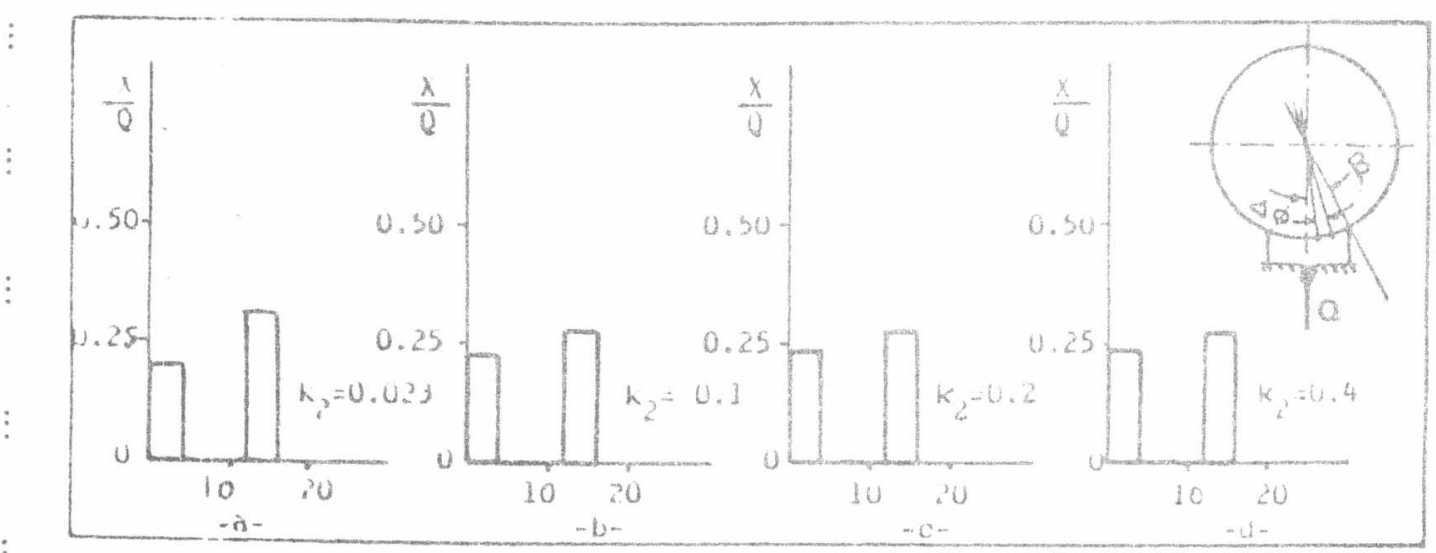

fig.6. Interiace pressure distribution for not welded sadule, aifferent values of $k_{2}$ and $\left(h_{1}=0.02372, \beta-16^{\circ}, \quad 0=0.036,0 \phi=44^{\circ}\right)$ due to urit radial load. 


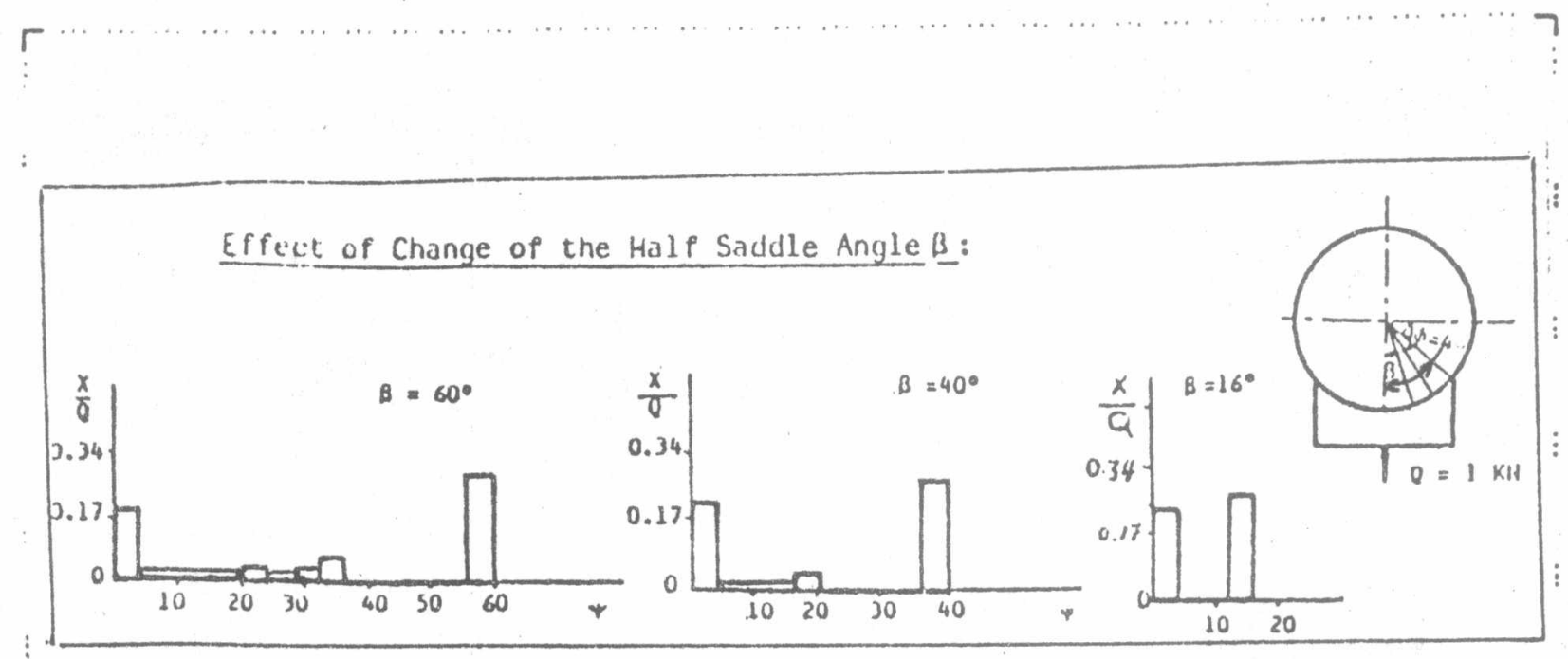

Fig. 7. Interface pressure distrlbutlon for not welded saddle and $k_{2}=0.4, k_{1}=0.02372, \delta=0.036$ ) due to unit radlal load.

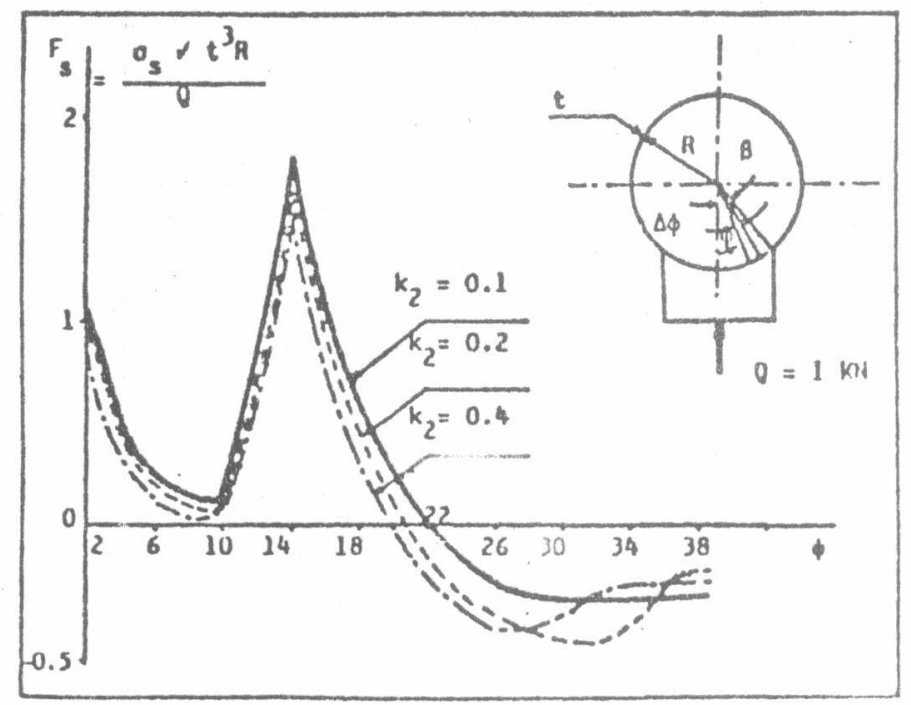

Flg. 8 Varlation of stress coefplclent $F_{9}$ for $\left(k_{1}=0.0 ? 3\right)$; $\left.\delta=0.036, B=16^{\circ}, \Delta \phi=4^{\circ}\right)$ and deperent value of end Pactor $k_{2}$. 


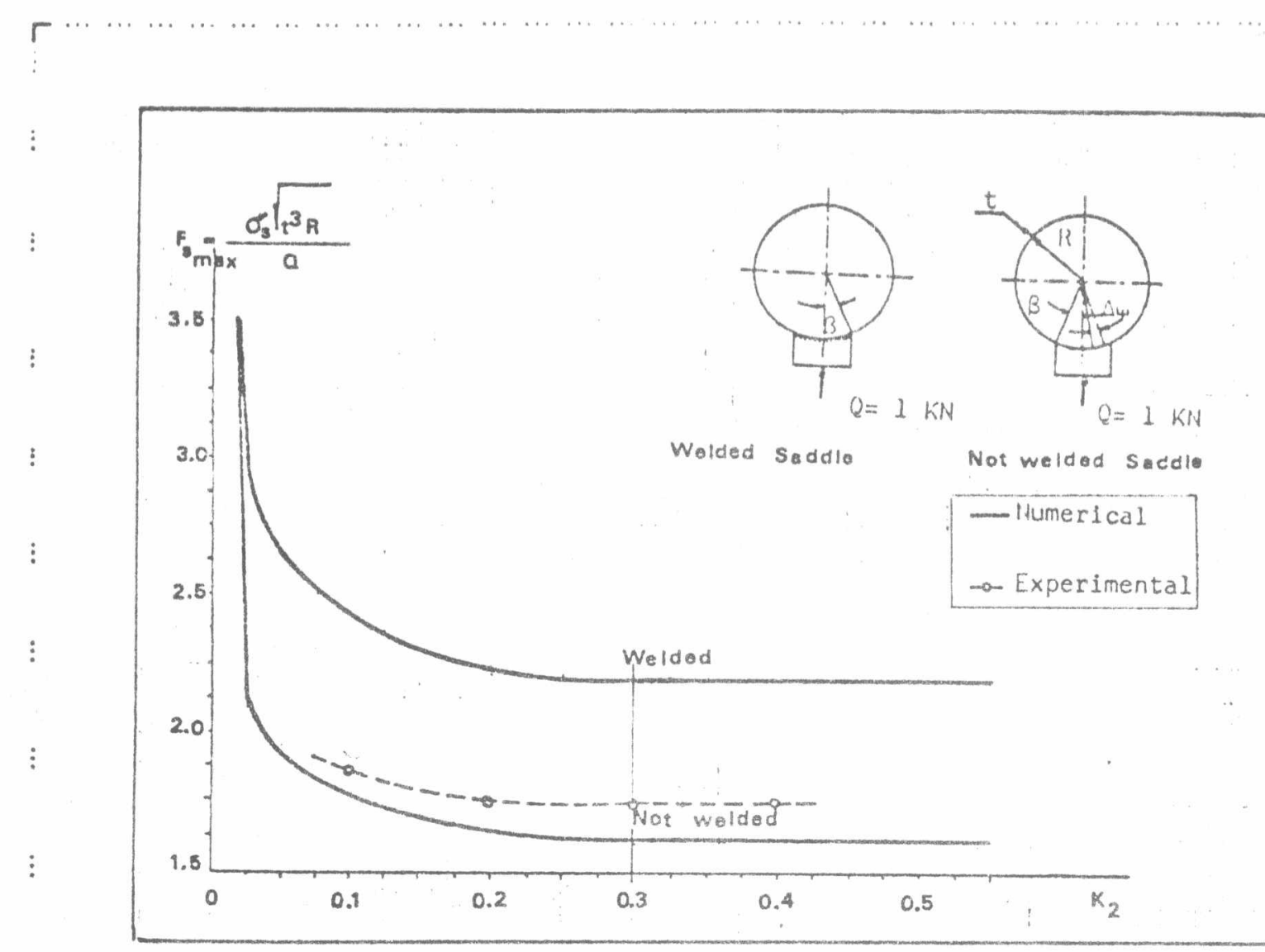

Fig.s Varlation of the max. stress coefficient at the saddle horn $\left(\phi=14^{\circ}\right) F_{\text {smax. }}$ with end factor $k_{2}$ for $\left(\beta=16^{\circ}, k_{1}=0.02372\right.$, $\delta=0.036$ )

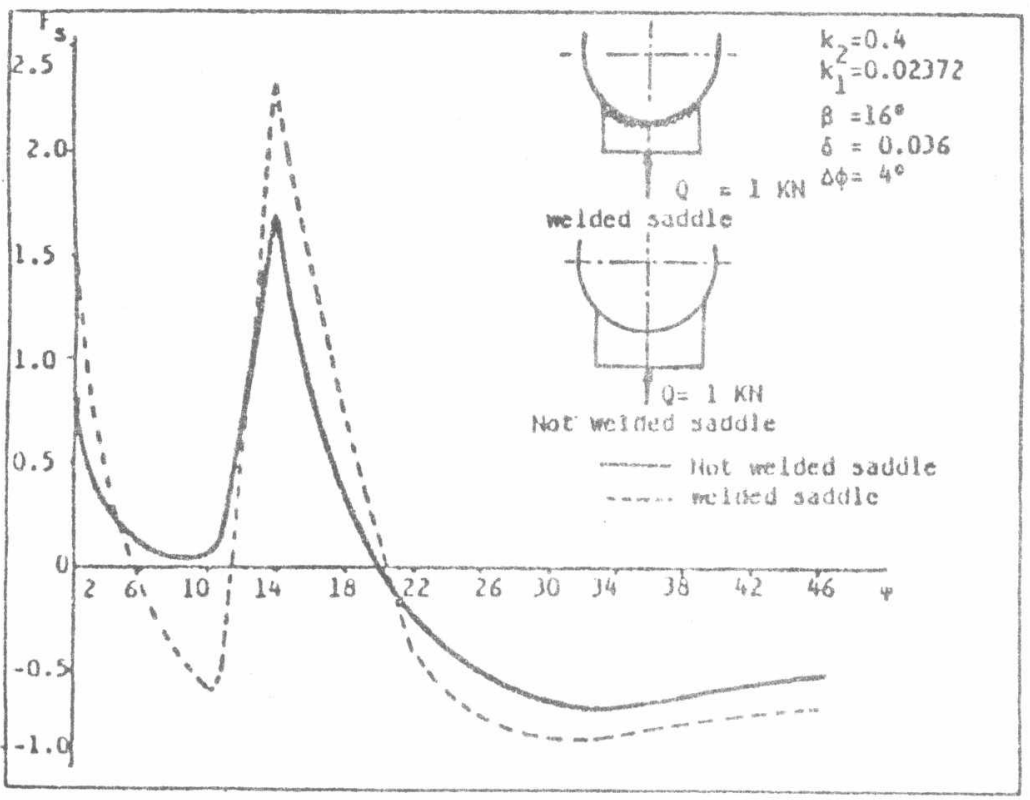

Fig. 10 Vartation of clrcumferential stress coeppletent $f_{s}$ for melded and not welded saddle. 


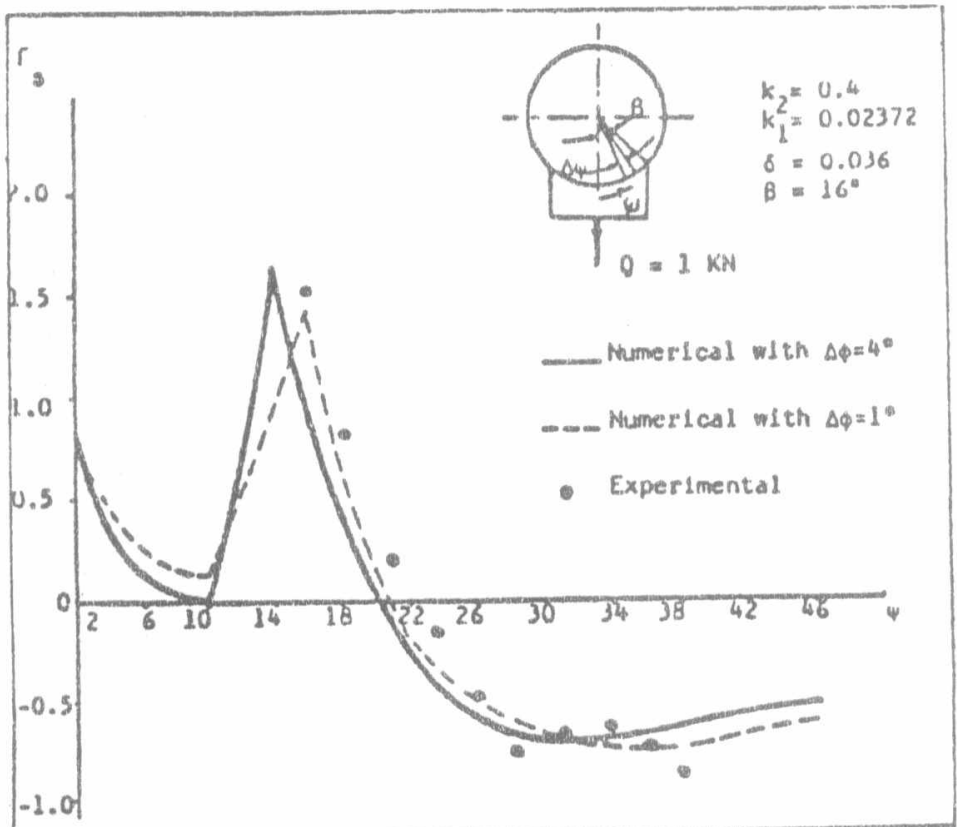

$\vdots$

$\vdots$

Flg. 12. Experdmental and numerlcal stress coepldclent F, whth w for not welded saddle.

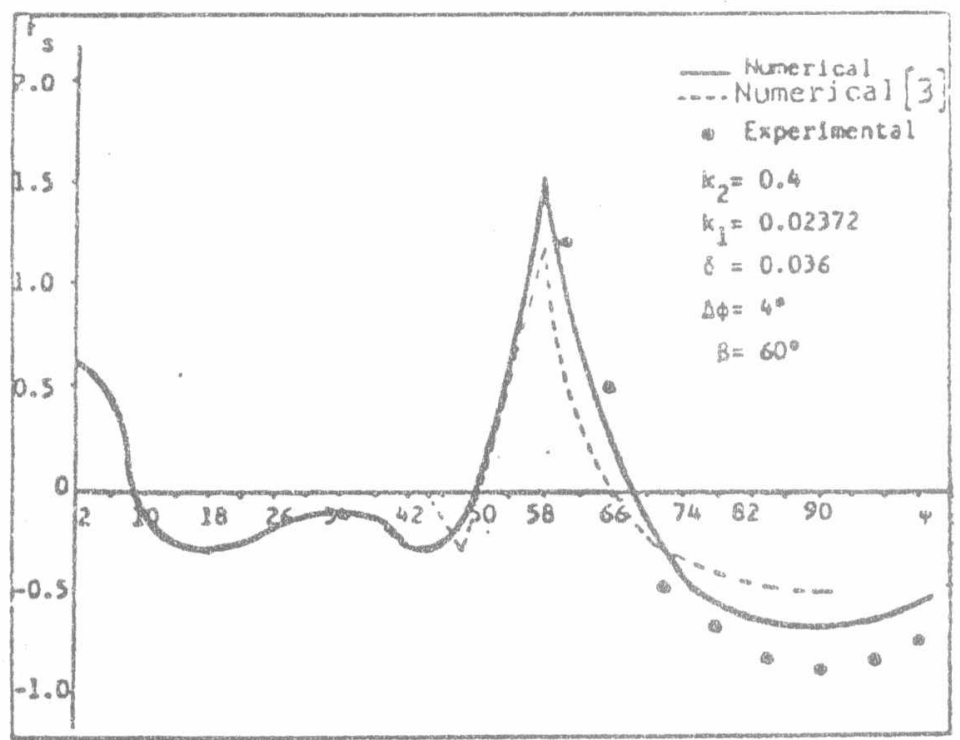

Flg. 12. Munerlcal and experimental wtress coepiclent $f_{g}$ for not welded saddle and halp saddle angle $6=60^{\circ}$ 


\section{$r$}

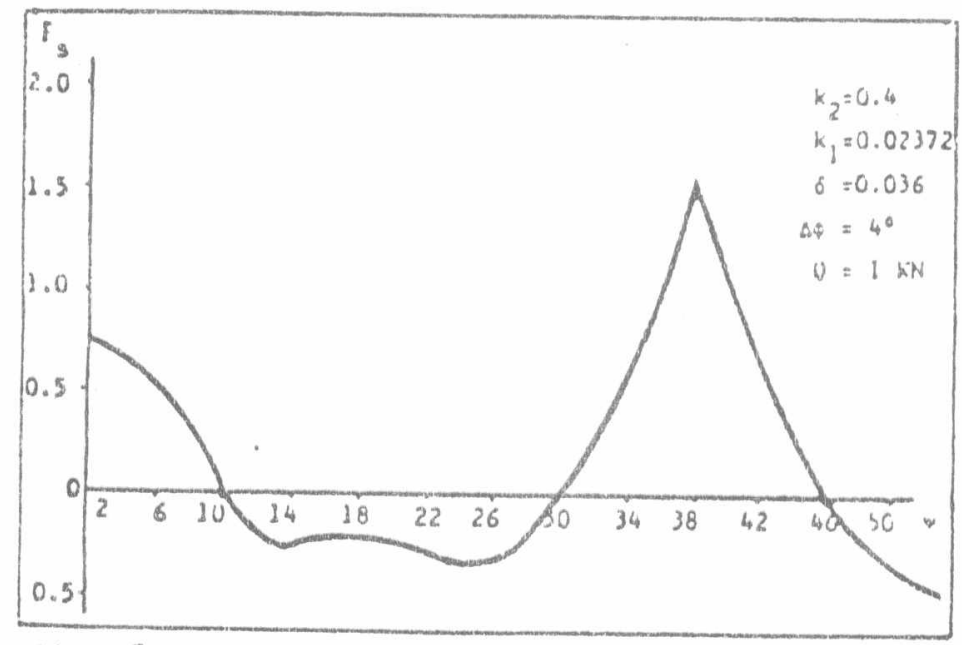

F18. 13. Vartation of stress coeppiclent $f$ por half saddlc angle $\theta=40^{\circ}$ and not lded saddle.

\section{REFERENCES}

1. Katan. L.I. and Makeev, E.M., "Contact problem for cylindrical shell resting on circular supportes of arbitrary length "Soviet Applied Mechanics spt. 1979.

2. Krupka, V. "contact between a rigid of flixible saddle and thin elastic shell. "Institute of Appl. Mech. 1975.

3. Momeh, $Z$. and El-Nomrossy M., "Radial and Tangential saddle cylinder interface pressure in contact problem of shells "l8th Annual Metting, society of Engineering science, Brown University 1981.

4. Vient, R. and Dore, R. "stresses and deformations in a cylindrical shell lying on a continuous rigid support" 3. of Applied Mechanics, Decemter: 1974.

5. Wilscn, J.D. and Tooth A.S., "The support of unstiffened : cylindrical vessel", pressure vessel technology, second International conference, Texas 0ct., 1973.

6. Zick, L.P., "Stresses in large Horizontal cylindrical pressure Vessels on two Saddle supports, JnL. As weld, Vol. 30, pp. $435-444,1951$.

7. Momeh, Z., Contact Problems of Dies with Cylindnical Shells." Candidate Dissertatim Work, Antonin Zäpotocky Military Academy, Brno 1974, Check. 